\title{
BENEFITS OF EARLY POST-ERCP LAPAROSCOPIC CHOLECYSTECTOMY: A SINGLE CENTRE PROSPECTIVE STUDY
}

Farhan Javeda, Saira Saleem ${ }^{b}$, Ayesha Rehmanc, Faiza Wattoo ${ }^{d}$, Nadia Banoe, Nazim Hayat ${ }^{f}$ ${ }^{a}$ Assistant Professor, Department of Surgery, Abu Ammara Medical College Lahore.

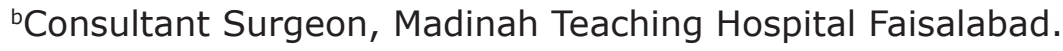

${ }^{\mathrm{c} A s s i s t a n t ~ P r o f e s s o r, ~ D e p a r t m e n t ~ o f ~ S u r g e r y, ~ A b u ~ A m m a r a ~ M e d i c a l ~ C o l l e g e ~ L a h o r e . ~}$ dPathologist, Madinah Teaching Hospital Faisalabad.

eConsultant Anesthesia, Madinah Teaching Hospital Faisalabad.

fProfessor, Department of Surgery, Abu Ammara Medical College Lahore.

\section{ABSTRACT:}

BACKGROUND \& OBJECTIVE: Laparoscopic cholecystectomy (LC) following Endoscopic retrograde cholangiopancreatography (ERCP) is associated with an increased risk of complications. ERCP is associated with increased incidence of complications during LC. Surgery may be performed in same anesthesia with ERCP or up to 6 weeks later. We aimed to determine the benefits of performing LC within $72 \mathrm{hrs}$ of ERCP.

METHODOLOGY: After institutional ethical approval this prospective cross-sectional study was performed at Madinah Teaching Hospital Faisalabad from April 2019 to June 2020. By performing convenience sampling, all patients undergoing LC after uneventful ERCP in our hospital were included. Study population was divided based on interval between ERCP and Cholecystectomy; Group-A had LC within $72 \mathrm{hrs}$ of ERCP, Group B had LC in same hospital stay after $72 \mathrm{hrs}$ and Group-C patients were discharged after ERCP and readmitted for LC. Data was collected using custom designed questionnaire, tabulated using Microsoft Excel 2016 and subjected to statistical tests to compare outcomes. Primary outcome was incidence of complications, while operative time, hospital stay and cost were considered as secondary outcomes. p-value of $<0.05$ was considered significant.

RESULTS: Total 75 patients were included in study, 32 in Group-A, 20 in Group-B and 23 in Group-C. Average age was $44.987 \pm 14.819$ and study population was predominantly female $(86.67 \%)$. Complication rate, duration of hospital stay and average cost were less in Group. A as compared to other groups $(p<0.05)$. Mean operative time in 3 groups was similar.

CONCLUSION: LC within $72 \mathrm{hrs}$ after ERCP provides superior results in terms of fewer complications, shorter hospital stays and lesser cost.

KEYWORDS: ERCP, Laparoscopic Cholecystectomy, Time-to-treatment, Postoperative care.

\section{How to cite this:}

https://doi.org/10.37723/jumdc.v12i3.567

Javed F, Saleem S, Rehman A, Wattoo F, Bano N, Hayat N. Benefits of early post-ERCP Laparoscopic Cholecystectomy : A single Centre Prospective Study. Journal of University Medical \& Dental College. 2021;12(3):177-184. https://doi.org/10.37723/jumdc.v12i3.567

This is an Open Access article distributed under the terms of the Creative Commons Attribution License (http://creativecommons.org/licenses/by/4.0), which permits unrestricted use, distribution, and reproduction in any medium provided the original work is properly cited. 


\section{INTRODUCTION:}

Incidence of cholelithiasis and choledocholithiasis is on a rise ${ }^{[1]}$, both coexisting in $15-20 \%$ patients ${ }^{[2,3]}$. Choledocholithiasis itself or its treatment by Endoscopic retrograde cholangiopancreatography (ERCP) and sphincterotomy ${ }^{[1]}$ may lead to acute cholangitis or acute pancreatitis ${ }^{[3]}$, increasing the likelihood of complications during subsequent laparoscopic cholecystectomy (LC) ${ }^{[4]}$.

ERCP and advanced laparoscopic equipment and expertise have rendered open techniques like common bile duct (CBD) exploration or bilioenteric bypass virtually obsolete for treatment of choledocholithiasis ${ }^{[2]}$. Now the norm is to perform ERCP for CBD stones followed by LC for cholelithiasis $^{[2]}$. Post-ERCP a cholangiogram or cholangioscopy can also be performed to confirm clearance of $\mathrm{CBD}^{[5]}$. ERCP itself has documented complication rate of $3-9 \%{ }^{[6]}$. Sphincterotomy and injection of dye increases chances of bacterial contamination of hepato-biliary tree ${ }^{[7]}$. Placement of endoscopic stents has also been associated with certain complications, especially peri ductal or ductal inflammation leading to adhesion formation and difficult dissection during LC later on ${ }^{[8]}$. This inflammatory response takes a few days to develop and a couple of weeks afterwards to settle ${ }^{[3]}$.

In patients with concomitant cholelithiasis and choledocholithiasis, the previously practiced procedure was to perform an ERCP followed by LC 6 weeks later ${ }^{[1]}$. But sometimes patients may require multiple sessions of ERCP to clear the $\mathrm{CBD}^{[9]}$. Moreover as ERCP \& other hepatobiliary procedures are associated with increased chances of pancreatitis and procedure related complications ${ }^{[4]}$, this approach was thought to give adequate time for edema and inflammation to settle ${ }^{[10]}$ and identification and management of ERCP related complications like acute pancreatitis. This trend of interval LC is changing. Researchers in various institutes globally are practicing reduced interval between ERCP and $\mathrm{LC}^{[11]}$. Performing an early surgery has the advantage of intervening before inflammatory response has set in. LC done in the same hospital admission reduces duration of hospital stay and decreases the chance of recurrent CBD stones ${ }^{[10]}$ which is otherwise encountered in $4-24 \%$ patients $^{[12]}$.

\section{Corresponding Author:}

Dr. Farhan Javed

Assistant Professor, Department of Surgery, Madinah Teaching Hospital Faisalabad.

Email: farhan_javed7@hotmail.com

As confidence in this technique has strengthened, some researchers advocate performing the two procedures simultaneously on the same day, under a same anesthesia[13]. This further reduces the length of hospital stay and reduces treatment cost imparted to the patient. But this also has some limitations, as in our setup ERCP is performed in prone position with adequate sedation but without intubation and LC is being performed in supine intubated patient. LC done the day after ERCP or within the same hospital stay with 48-72 hours gap confers adequate advantages for it to be considered a suitable alternate to 6 weeks' delay. At our institute the norm has been to perform interval cholecystectomy with a minimum gap of 3 weeks between ERCP and LC. In the past year we have tried to shift our practice to perform LC earlier i.e., within the same hospital admission.

The aim of this study was to compare the results of early post-ERCP LC to those performed later. We wish to compare whether early LC has any advantage in terms of operative time, rate of complication, duration of hospital stays and procedural costs.

\section{METHODOLOGY:}

After approval from ethical review committee (TUF/Dean/2020/190) of our institute, data was collected prospectively from patients admitted in Madinah Teaching Hospital Faisalabad for ERCP and post-ERCP LC. Patients of both genders and all age were included. Patients who underwent uneventful ERCP (no procedure related complication or post-procedure peritonism/ peritonitis/pancreatitis) and subsequently LC at our hospital between April 2019 and June 2020 were included in the study irrespective of the duration between the two procedures. Patients who had ERCP but did not return for LC during this time or those that had ERCP at some other hospital and presented to us for LC were 
excluded. Patients were then grouped into three categories. Group-A had LC within $72 \mathrm{hrs}$ after ERCP; Group-B had ERCP and LC in the same hospital stay but the duration between the two procedures was more than 72hrs; and Group-C who were discharged after ERCP and then readmitted later for $\mathrm{LC}$. All the data was collected using a custom designed form. These forms were filled by the researchers themselves. The collected data was then subjected to statistical analysis, Mean and standard deviation were calculated for variables like patients age, duration between ERCP and LC, number of days of hospital stay and cost of treatment. Frequency distribution and percentage was calculated for co-morbid factors, previous abdominal surgery and complications of LC. The primary outcome variable used to compare groups was any operation related complications (hemorrhage, conversion to open, injury to any other viscera, post-op peritonitis). Secondary outcomes observed were total time of surgery (time between first skin incision and last stitch) which was recorded in the operation notes and, duration of hospital stay (duration of stay for ERCP and LC combined) and total cost of treatment (combined cost of ERCP \& LC, medications and hospital expenses). Data was tabulated using Microsoft Excel and SPSS software and appropriate statistical tests (Chi square test, one-way ANNOVA test, Fischer's exact test, Krukal Wallis test) were applied on the tabulated data. p-value of less than 0.05 was taken as significant.

\section{RESULTS:}

Total number of patients included in our study was 75, Mean age being 44.987 14.819 years. The study population consisted predominantly of females, the male to female ratio being $1: 6.5$. The chief presenting complain was upper abdominal pain localized to epigastrium and right hypochondrium in $86.67 \%$ patients (Figure-I). Patients with comorbid condition like Diabetes, Pancreatitis and hypertension were 11 $(14.67 \%)$, the most prevalent being diabetes seen in 5 individuals (6.67\%). Six patients (8\%) had history of previous abdominal surgery most commonly a lower segment cesarean section.

The average size of stone in CBD for which ERCP was done was $7.751 \pm 5.599 \mathrm{~mm}$. Only 2 patients required a second session of ERCP. Clearing of CBD was documented in all patients by occlusion cholangiogram. No patient had stenting or cholangioscopy done. Most patients $(n=52$, $69.33 \%$ ) were shifted to surgery ward for LC, remaining $(n=23,30.67 \%)$ were discharged and later re-admitted for LC. No patient in our study had recurrence of $C B D$ stone in the duration between ERCP and LC.

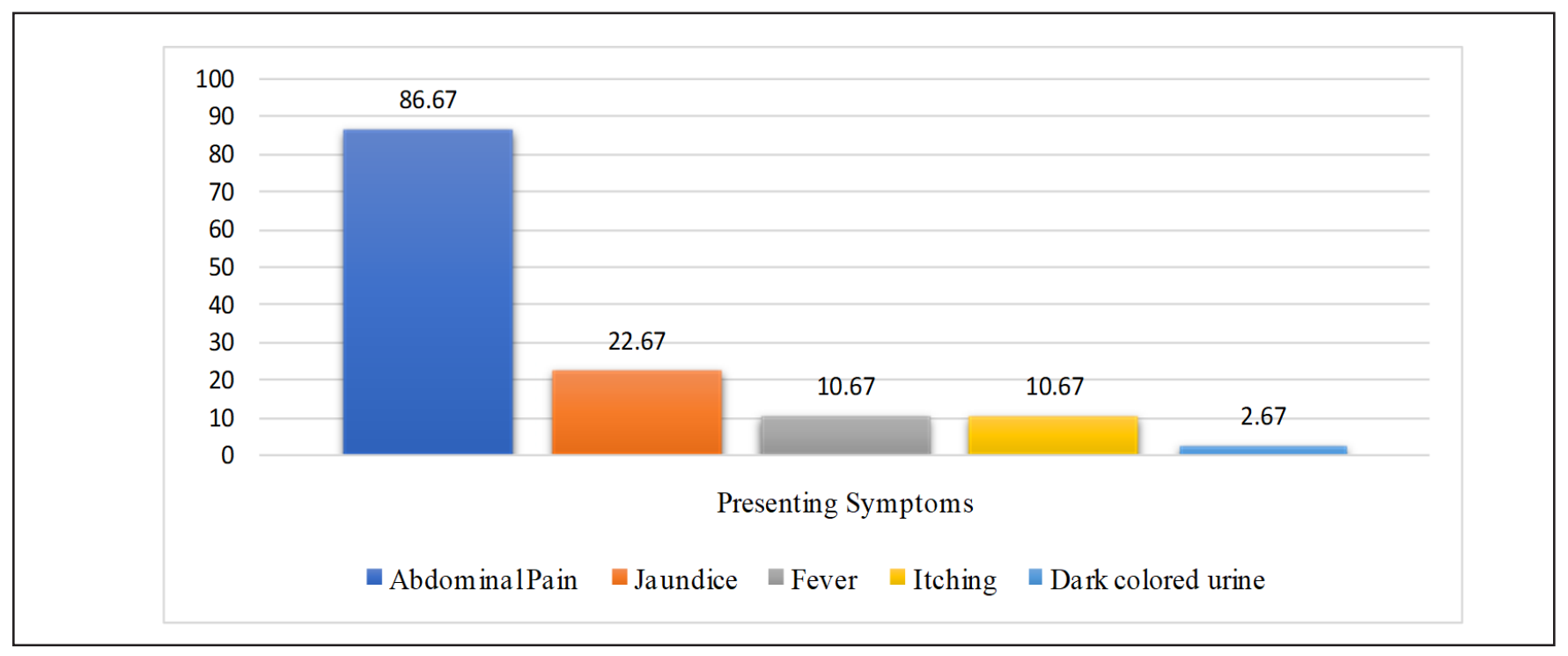

Figure-I: Distribution of Symptoms among Study Population. 
From the gathered data, key variables considered were operative time (time from the first skin incision to the last stitch documented in the operation notes); any intra or post-operative complications like conversion to open, excessive hemorrhage or peritonitis; duration of hospital stay (time spent in gastro ward for ERCP and in surgery ward for LC); interval between ERCP and LC and total cost of treatment (including the cost or ERCP and LC, medications and other hospital expenses).

In Group-A, total number of patients was 32 . Average age was calculated to be $47.562 \pm$ 15.678 years. Male to female ratio was $1: 5.33$. in this group, $2(6.25 \%)$ patients had diabetes and 2 patients $(6.25 \%)$ had history of previous abdominal procedure. On average, the delay between ERCP and LC was 1.875 days, ranging between 1 and 3 days. The operative time for Group-A individuals was $36.125 \pm 9.584$ mins. In this group, no conversion to open procedure was done. No post-operative complication was seen in individuals of this group. Duration of hospital stay in Group A patients was found to be $8.750 \pm$ 2.396 days. The total cost incurred to the patient on average was $70,987 \pm 10,612$ PKR.

Number of patients included in Group-B was 20. Average age was $45.400 \pm 10.231$ years, male to female ratio being 1:9. Duration between ERCP and LC was 5.3 days ranging from 4 to 9 days. Known comorbid factors were present in 4
(20\%) patients. History of abdominal procedures was found in $4(20 \%)$ patients. Operative time was calculated $42.000 \pm 14.179$ mins. In this group, 3 patients $(15 \%)$ had to be converted to open procedure due to difficult dissection at Callot's triangle owing to adhesions. All cholecystectomies were successfully completed and no complications were observed in postoperative time. Average hospital stay in this group came out to be $16.100 \pm 5.139$ days and average cost was $80,363 \pm 13,226$ PKR.

In Group-C, 23 patients with average age of $41.043 \pm 16.587$ years were included. Male to female ratio was $1: 10.5$. Average duration between ERCP and LC was calculated to be 21.08 days ranging between 9 to 34 days. Co-morbid diseases were present in 5 patients $(21.73 \%)$ and no patients had history of previous abdominal procedures. Calculated operative time in this group was $34.61 \pm 8.63$ mins. No conversion to open procedure was recorded. However, 1 patient $(4.35 \%)$ developed post-operative peritonitis and had to undergo exploratory laparotomy for biliary peritonitis. Total duration of hospital stay was calculated to be $12.826 \pm 4.489$ days with average cost being $75,357 \pm 17,836$ PKR.

The comparison of important clinical features is shown in Table-I. Age and gender related distribution in all groups is similar and difference is statistically insignificant.

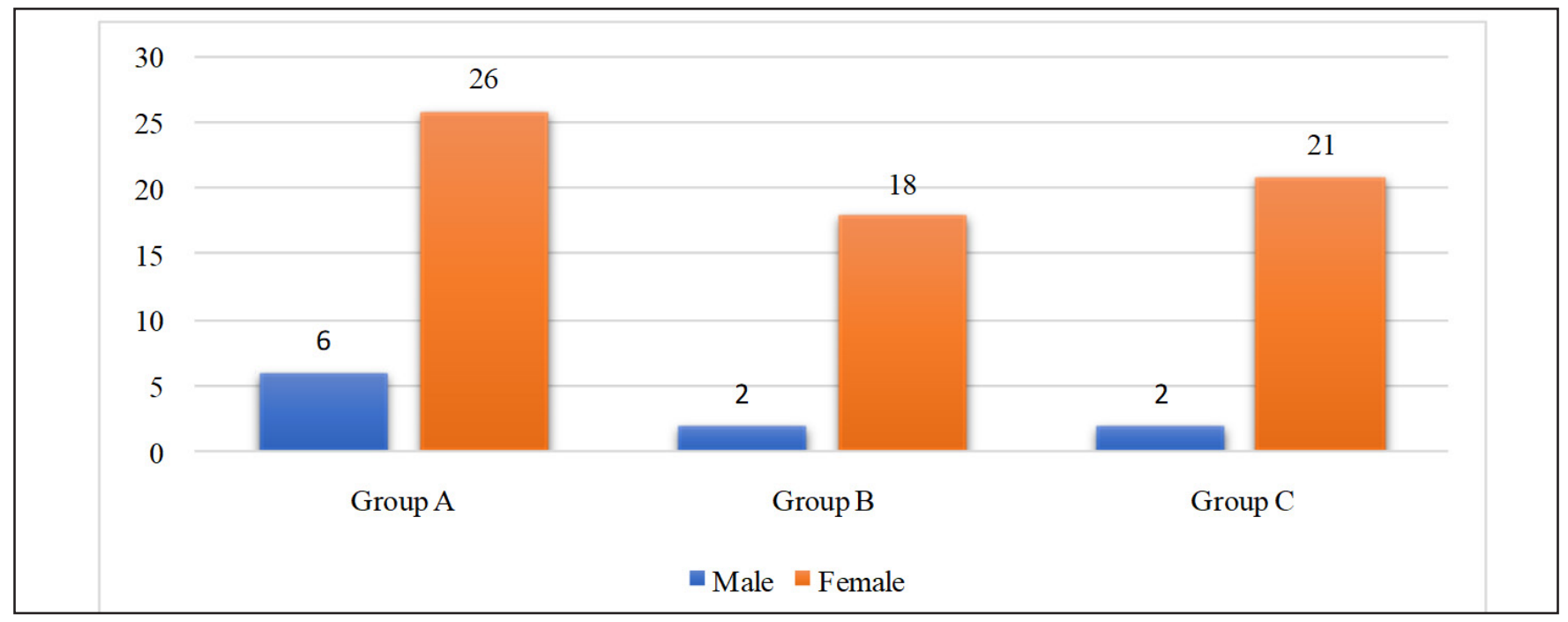

Figure-II: Gender Related Distribution of Study Population. 
The distribution of co-morbid factors and previous abdominal procedures among the three groups was also similar. As these procedures were lower abdominal surgeries, they did not have any significant effect on surgical anatomy of hepatobiliary system or operative outcome.

a One-way ANOVA test is applied.

${ }^{\mathrm{b}}$ Chi-square test.

cFisher's Exact Test.

( $p<0.05$ taken as significant)

The comparison of study groups in reference to primary study variables is shown in Table-II.
The results show that there is statistically significant difference in terms of complication rates, hospital stay and treatment cost. The difference in operative time, however did not show any statistically significant difference. Group-A showed the best results with least complications, shortest duration of hospital stay and minimum average procedural cost. Group-B had the maximum percentage of complications, longest hospital stay and highest procedural cost. Group-C showed results better than Group-B, but still not as good as Group-A.

Table-I: Comparison of clinical features of study groups.

\begin{tabular}{|c|c|c|c|c|c|}
\hline \multirow{2}{*}{\multicolumn{2}{|c|}{$\begin{array}{l}\text { Age (Years) } \\
\text { Mean } \pm \text { SD }\end{array}$}} & $\begin{array}{l}\text { Group-A } \\
(n=32)\end{array}$ & $\begin{array}{c}\text { Group-B } \\
(n=20\end{array}$ & $\begin{array}{l}\text { Group-C } \\
(n=23)\end{array}$ & p-value \\
\hline & & $47.562 \pm$ & $45.400 \pm$ & $41.043 \pm 16.587$ & 0.274 \\
\hline \multirow{2}{*}{$\begin{array}{l}\text { Gender }^{b} \\
\text { N (\%) }\end{array}$} & Females & $\begin{array}{c}26 \\
(81.25 \%)\end{array}$ & $18(90 \%)$ & $21(91.30 \%)$ & \multirow[t]{2}{*}{0.488} \\
\hline & Male & $6(19.75 \%)$ & $2(10 \%)$ & $2(8.70 \%)$ & \\
\hline \multirow{2}{*}{$\begin{array}{l}\text { Co-Morbid } \\
\text { conditions } \\
\text { N }(\%)\end{array}$} & Present & $2(6.25 \%)$ & $4(20 \%)$ & $5(21.73 \%)$ & \multirow{2}{*}{0.297} \\
\hline & Absent & $\begin{array}{c}31 \\
(93.75 \%)\end{array}$ & $16(80 \%)$ & $18(78.27 \%)$ & \\
\hline \multirow{2}{*}{$\begin{array}{c}\text { Previous Surgeryc } \\
\text { N (\%) }\end{array}$} & Present & $2(6.25 \%)$ & $4(20 \%)$ & 0 & \multirow{2}{*}{0.052} \\
\hline & Absent & $\begin{array}{c}31 \\
(93.75 \%)\end{array}$ & $16(20 \%)$ & $23(100 \%)$ & \\
\hline
\end{tabular}

aFischer's Exact Test, bOne-way ANOVA test, cKruskal-Wallis Test, * Statistically significant $(p<0.05$ taken as significant).

Table-II: Comparison of variables among study groups.

\begin{tabular}{|c|c|c|c|c|c|}
\hline & & $\begin{array}{c}\text { Group-A } \\
(n=32)\end{array}$ & $\begin{array}{c}\text { Group-B } \\
(n=20\end{array}$ & $\begin{array}{c}\text { Group-C } \\
(n=23)\end{array}$ & p-value \\
\hline \multirow{2}{*}{ Complications ${ }^{a}$} & Present & 0 & $3(15 \%)$ & $1(4.35 \%)$ & \multirow{2}{*}{$0.032 *$} \\
\hline & Absent & $32(100 \%)$ & $17(85 \%)$ & $22(95.65 \%)$ & \\
\hline \multicolumn{2}{|c|}{ Operative Time (mins) ${ }^{b}$} & $36.125 \pm 9.584$ & $42.000 \pm 14.179$ & $34.61 \pm 8.63$ & 0.065 \\
\hline \multicolumn{2}{|c|}{ Hospital Stay (Days) } & $8.750 \pm 2.396$ & $16.100 \pm 5.139$ & $12.826 \pm 4.489$ & $<0.001^{*}$ \\
\hline \multicolumn{2}{|c|}{ Procedural Cost (PKR)c } & $70,987 \pm 10,612$ & $80,363 \pm 13,226$ & $75,357 \pm 17,836$ & $<0.036 *$ \\
\hline
\end{tabular}

aFischer's Exact Test, bOne-way ANOVA test, cKruskal-Wallis Test, * Statistically significant $(p<0.05$ taken as significant). 
Our study results showed that best results are achieved when LC is done within $72 \mathrm{hrs}$ after ERCP with least percentage of complications, shortest hospital stay and minimum average cost per patient. Interval LC also produces relatively suitable results but not as good.

\section{DISCUSSION:}

As cholelithiasis is mainly a disease of female population ${ }^{[14]}$, it is no surprise that incidence of choledocholithiasis is also more in female population ${ }^{[15]}$. Our study population comprised mostly of female patients being $86.67 \%$ of total with an average age of almost 45 years. Similar data has been reported by multiple other authors ${ }^{[2,7]}$. However, European studies show a different demographic data as seen in the work of Bass et $\mathrm{al}^{[6]}$ who described variations in incidence, complications and surgical practices related to gall stone disease in different European populations. They found a mean age of 65 years and $54 \%$ subjects being females. This difference in European and south Asian populations can be described by a difference in genetic predisposition to certain disorders, dietary preferences and lifestyle in general.

The clinical presentations of our patients were similar to those found by Wilkins $\mathrm{T}$ al[3]. Their work was more focused on presentation and treatment of cases of acute cholangitis secondary to choledocholithiasis. In our patients, prophylactic antibiotic cover along with fluids and analgesics was given routinely to all patients undergoing ERCP and LC. This regimen is similar to proposed treatment of acute cholangitis ${ }^{[3]}$, subsequently we found less cases of cholangitis. It is difficult to determine whether this prophylactic regimen prevented acute cholangitis or it treated established infection.

The average size of CBD stone for which ERCP was performed in our study was found to be 7.75 $\pm 5.6 \mathrm{~mm}$ and a very small percentage required a repeat ERCP for complete CBD clearance. Other researchers found average stone size of $7.5 \pm 4.5 \mathrm{~mm}{ }^{[12]}$ and established that stone size greater than $10 \mathrm{~mm}$ is a risk factor for recurrence of CBD stone. Steps of ERCP were also similar in both studies with complete CBD clearance rarely requiring a second ERCP.

Distribution of patients in our study into three groups is similar to other studies[7,10]. Some studies have distributed subjects into further groups all based on duration between ERCP and LC ${ }^{[16,17]}$. General consensus of all researchers seems to be that sooner is better. Most researchers suggested the ideal timing of LC within $24 \mathrm{hrs}^{[17]}$, within 2 days ${ }^{[16]}$ or on the third day ${ }^{[7]}$ after ERCP. All agree that a delay in LC is associated with an increased incidence of acute cholecystitis ${ }^{[18]}$, recurrence of CBD stone ${ }^{[12]}$, ascending cholangitis ${ }^{[3]}$ and operation related complications like injury to biliary tree or conversion to open procedure ${ }^{[17]}$. Our study results also support this outcome. We found that the most suitable time to perform LC in our setup is within 3 days after ERCP. The gap of 6 weeks as suggested by some authors ${ }^{[1]}$ and previously practiced at our institute gives inferior results as compared to those found in patients who were operated within $72 \mathrm{hrs}$ of ERCP. Our study also suggested that duration between 3 days and 6 weeks is the most unsuitable approach for the patients as it gave the worst results in terms of rate of conversion to open, duration of hospital stay and cost of treatment.

Comparison of individual groups between our study and work of Aziret $\mathrm{M}$ at $\mathrm{al}^{[7]}$ is also similar. Both studies had a female predominance, our study having a slightly greater female to male proportion. Previous studies on similar subjects in Pakistan found similar gender and age-related distribution of subjects ${ }^{[2,14]}$. The average age of our subjects was less than that calculated by foreign researchers ${ }^{[7]}$. This may be attributed to different dietary patterns. It may also contribute to a relatively younger study population having a lower incidence of co-morbid conditions which is shown by an overall lower incidence of diabetes, hypertension and other conditions in our study population.

The average operation time in all the three groups of our study was less as compared to other local studies ${ }^{[19]}$ and difference among the group was statistically insignificant. Some authors ${ }^{[7]}$ have found a statistically significant difference proving that LC done earlier takes less time. Regarding 
hospital stay, our group-B and $C$ patients had a longer stay as compared to group A which was in contradiction to previously published work ${ }^{[7]}$ that found almost similar length of hospital stay in all groups. We did not record any complication in Group-A patients. Most complications were seen in Group-B patients. Other researchers also corroborate these findings. LC done earlier encounter less complications and the rate of complications increases with duration of delay[17]. The data suggests that complications increase the duration of stay and cost of treatment, however these results will require further research.

To summarize, our study results and literature search support the idea of performing LC within 72 hrs of ERCP to minimize operative time, risk of complications, duration of hospital stay and average cost of treatment. Interval LC still remains a viable option with second-best results. Whether ERCP done under same anesthesia will increase this benefit still needs to be studied further. Also, our study population was small and data collection failed to record subjective impression of surgeons and patients both of which need to be considered in subsequent work on this topic. A case control study with larger sample size may be useful to further elaborate advantages of this technique.

\section{CONCLUSION:}

Our study was successful in concluding that overall risk of operative complications is reduced by performing LC within 72 hours of ERCP. In addition, early LC also reduces duration of hospital stay and cost of treatment. Operative time is not significantly affected by interval between ERCP and LC.

ACKNOWLEDGEMENT: The authors wish to thank Professor Dr. Irshad Ahmad Head of Surgery Department for his guidance in conceptualizing and completion of this article. We also acknowledge contribution of Department of Gastroenterology, specifically Prof Dr Shahid Rasool and Dr Umair Shafqat for being helpful in guiding patients.
CONFLICT OF INTEREST: None. GRANT SUPPORT \& FINANCIAL DISCLOSURE: None.

\section{REFERENCES:}

1. Mann K, Belgaumkar AP, Singh S. Postendoscopic retrograde cholangiography laparoscopic cholecystectomy: challenging but safe. Journal of Society of Laproendoscopic Surgeons. 2013;17(3):371-375.

2. Ghazanfor $R$, Liaqat $N$, Changeez $M$, Tariq M, Malik S, Ghazanfar KR, et al. Choledocholithiasis: Treatment Options in a Tertiary Care Setup in Pakistan. Cureus. 2017;9(8):e1587.

3. Wilkins T, Agabin E, Varghese J, Talukder A. Gallbladder dysfunction: cholecystitis, choledocholithiasis, cholangitis, and biliary dyskinesia. Primary Care: Clinics in Office Practice. 2017;44(4):575-597.

4. Senocak R, Celik SU, Kaymak S, Hancerliogullari O. Perioperative outcomes of the patients treated using laparoscopic cholecystectomy after emergent endoscopic retrograde cholangiopancreatography for bile duct stones: Does timing matter? Ulusal Travma ve Acil Cerrahi Dergisi. 2020;26(3):396-404.

5. Maydeo AP, Rerknimitr R, Lau JY, Aljebreen A, Niaz SK, Itoi T, et al. Cholangioscopyguided lithotripsy for difficult bile duct stone clearance in a single session of ERCP: results from a large multinational registry demonstrate high success rates. Endoscopy. 2019;51(10):922-929.

6. Bass GA, Gillis A, Cao Y, Mohseni S. European Society for Trauma ESCSG. Patterns of prevalence and contemporary clinical management strategies in complicated acute biliary calculous disease: an ESTES 'snapshot audit' of practice. European Journal of Trauma and Emergency Surgery. 2020:1-3.

7. Aziret $M$, Karaman $K$, Ercan M, Vargol $E$, Toka B, Arslan Y, et al. Early laparoscopic cholecystectomy is associated with less risk of complications after the removal of common bile duct stones by endoscopic retrograde cholangiopancreatography. Turkish Journal of Gastroenterology. 2019;30(4):336-344. 
8. Taj MA, Ghazanfar S, Qureshi S, Zubair M, Niaz SK, Quraishy MS. Plastic stent migration in ERCP; a tertiary care experience. Journal of Pakistan Medical Association. 2019;69(8):1099-1102.

9. Dasari BV, Tan CJ, Gurusamy KS, Martin DJ, Kirk G, McKie L, et al. Surgical versus endoscopic treatment of bile duct stones. Cochrane Database of Systematic Review. 2013(9):CD003327.

10. El Nakeeb A, Ezzet H, Askar W, El Hanafy E, Hamdy E, Atef E, et al. Early Versus Late Cholecystectomy After Clearance of Common Bile Duct Stones by Endoscopic Retrograde Cholangiopancreatography: A Prospective Randomized Study. Surgical Laparoscopy Endoscopy \& Percutananeous Techniques. 2016;26(3):202-207.

11. Mohamed MA, Bahram MA, Ammar MS, Nassar $\mathrm{AH}$. One-Session Laparoscopic Management of Combined Common Bile Duct and Gallbladder Stones Versus Sequential ERCP Followed by Laparoscopic Cholecystectomy. Journal of Laparoendoscic and Advanced Surgical Techniques. 2015;25(6):482-485.

12. Konstantakis C, Triantos C, Theopistos V, Theocharis G, Maroulis I, Diamantopoulou $\mathrm{G}$, et al. Recurrence of choledocholithiasis following endoscopic bile duct clearance: Long term results and factors associated with recurrent bile duct stones. World Journal of Gastrointestinal Endoscopy. 2017;9(1):2633.

13. Fishman DS, Barth B, Mazziotti MV, Lazar DA, Brandt ML, Fallon SC, et al. Same anesthesia ERCP and laparoscopic cholecystectomy in the Pediatric ERCP Database Initiative (PEDI) Experience. Journal of Pediatric Gastroenterology and Nutrition. 2020.

14. Tanvir A, Javed F, Mahmood K, Rehan AG. Gall stone associated acute pancreatitis: A review of 50 patients. Journal of University Medical and Dental College. 2018;9(2):34-40

15. Zahur $Z$, Jeilani A, Fatima T, Ahmad A. Transabdominal Ultrasound: A Potentially Accurate And Useful Tool For Detection Of Choledocholithiasis. Journal of Ayub Medical College. 2019;31(4):572-575.
16. Blohm M, Osterberg J, Sandblom G, Lundell $L$, Hedberg M, Enochsson L. The Sooner, the Better? The Importance of Optimal Timing of Cholecystectomy in Acute Cholecystitis: Data from the National Swedish Registry for Gallstone Surgery, GallRiks. Journal of Gastrointestinal Surgery. 2017;21(1):33-40.

17. Friis C, Rothman JP, Burcharth J, Rosenberg J. Optimal Timing for Laparoscopic Cholecystectomy After Endoscopic Retrograde Cholangiopancreatography: A Systematic Review. Scandanavian Journal of Surgery. 2018;107(2):99-106.

18. Ting $\mathrm{PH}$, Luo JC, Lee $\mathrm{KC}$, Chen TS, Huang $\mathrm{YH}$, Hou MC, et al. Post-ERCP cholecystitis: Incidence and risk factors. Journal of Chinese Medical Association. 2020 ;83(8):733-736

19. Zarin M, Khan MA, Khan MA, Shah SAM. Critical view of safety faster and safer technique during laparoscopic cholecystectomy? Pakistan Journal of Medical Science. 2018;34(3):574-577.

\section{AUTHORS CONTRIBUTION:}

Farhan Javed: Study design, data collection, manuscript writing, and statistical analysis.

Saira Saleem: Conceptual framework, review and editing.

Ayesha Rehman: Data collection, analysis and interpretation.

Faiza Wattoo: Critical review and editing of manuscript.

Nadia Bano: Formalization of results and tables. Nazim Hayat: Design of the work and final approval of the version to be published.

Submitted for Publication: 25-01-2021 Accepted After revision: 21-06-2021 